\title{
SATISFAÇÃO DOS ALUNOS DE ADMINISTRAÇÃO COM O CURSO E SUA RELAÇÃO COM A IMAGEM DA IES ${ }^{1}$
}

\author{
SATISFACTION OF THE PUPILS OF ADMINISTRATION WITH THE COURSE AND ITS \\ RELATION WITH THE IMAGE OF THE IES
}

\author{
Janaina Lorenzi Tomio ${ }^{2}$ \\ Maria José Barbosa de Souza ${ }^{3}$
}

\begin{abstract}
RESUMO: Os desafios que caracterizam o ambiente em que as Instituições de Ensino Superior (IES) estão operando têm provocado modificações no sistema educacional do país. Essas modificações permitiram maior acesso ao ensino superior, mas, propiciaram o crescimento desordenado do número de vagas ofertadas nas universidades particulares, aumentando a competição do setor e levando à necessidade de realização de estudos sobre a imagem corporativa, pois a imagem positiva influencia a satisfação dos diversos públicos com as quais a instituição se relaciona. Com o objetivo de analisar a satisfação dos alunos de Administração com o curso e demais serviços oferecidos, bem como a imagem corporativa de uma instituição de ensino superior do estado de Santa Catarina, realizou-se um levantamento de caráter exploratório-descritivo com uma amostra de 1536 alunos do referido curso. A análise de dados foi feita por meio de tabelas de distribuição de freqüência, média e desviopadrão, cruzamento dos dados, teste ANOVA, teste de Tukey e Análise Fatorial de Correspondência Múltipla AFCM. Os dados da pesquisa demonstraram que os componentes cognitivos e afetivos da imagem são associados à satisfação e que a imagem percebida pelos discentes de uma universidade depende de sua satisfação. Essas evidências poderão auxiliar o novo posicionamento da universidade no mercado, frente ao cenário competitivo que as IES estão enfrentando atualmente, à medida que indica as variáveis que precisam ser aperfeiçoadas a fim de melhorar a imagem corporativa da organização e a satisfação dos alunos com os serviços educacionais oferecidos.
\end{abstract}

PALAVRAS CHAVES: marketing educacional, satisfação do consumidor e imagem corporativa.

ABSTRACT: The challenges that characterize the environment where the Institutions of Ensino Superior (IES) are operating have provoked modifications in the educational system of the country. These modifications had allowed to greater access to superior education, but, had propitiated the disordered growth of the vacant number offered in the particular universities, increasing the competition of the sector and leading to the necessity of accomplishment of studies on the corporative image, therefore the positive image influences the satisfaction of the diverse public with which the institution if relates. With the objective to analyze the satisfaction of the pupils of Administration with the offered course and too much services, as well as the corporative image of an institution of superior education of the state of Santa Catarina, a character survey was become fullfilled exploratorydescription with a sample of 1536 pupils of the related course. The analysis of data was made by means of tables of distribution of frequency, average and shunting line-standard, crossing of the data, has tested ANOVA, test of Tukey and Factorial Analysis of Multiple Correspondence - AFCM. The data of the research had demonstrated that the cognitive and affective components of the image are associates to the satisfaction and that the image perceived for the learning of a university depends on its satisfaction. These evidences will be able to assist the new positioning of the university in the market, front to the competitive scene that the IES are facing currently, to the measure that indicates the 0 variable that they need to be perfected in order to improve the corporative image of the organization and the satisfaction of the pupils with the offered educational services.

KEY WORD: educational marketing, satisfaction of the consumer and corporative image.

\footnotetext{
${ }^{1}$ Artigo publicado no EnEPQ - I Encontro de Ensino e Pesquisa em Administração e Contabilidade - Recife / PE 21 a 23 de novembro de 2007.

Artigo Recebido em 04.11.2008. Revisado por pares em 11.11.2008. Recomendado em 11.11.2008 por Denise Del Pra Netto Machado (editora). Publicado em 15.12.2008.

Organização Responsável pelo periódico: Universidade regional de Blumenau - FURB - www.furb.br/rn

${ }^{2}$ Mestre em Administração pela Universidade do Vale do Itajaí - Responsável pela Pesquisa, Pós-Graduação, Extensão e Cultura da Univali de Balneário Camboriú - janatomio@univali.br

${ }^{3}$ Doutora em Ciências da Comunicação - Professora de Mestrado em Turismo e Hotelaria no Mestrado

Acadêmico em Administração da Universidade do Vale do Itajaí - mjbsouza@matrix.com.br
} 


\section{INTRODUÇÃO}

As mudanças econômicas, políticas, culturais, sociais e tecnológicas ocorridas no cenário atual têm exigido uma reformulação de estruturas e estratégias por parte das organizações para se manterem competitivas (WOOD JR. e ZUFFO, 1998). Diante dessas forças ambientais, que conduzem as organizações a mudarem seus objetivos, metas e processos, encontram-se as Instituições de Ensino Superior (IES) que estão procurando apresentar um novo posicionamento de seus dirigentes em relação a esse panorama.

Para Müller (2005), o ambiente em que as Instituições de Ensino Superior (IES) atuam apresenta desafios que estão ocasionando modificações no sistema educacional do país. Embora essas modificações tenham permitido a democratização do acesso ao ensino superior, também estimularam o crescimento acelerado de vagas, ofertadas nas universidades particulares. Isso ocasionou o aumento da competitividade entre essas organizações no sentido de atrair e manter o número de alunos necessários para ocupar a capacidade instalada na instituição.

De acordo com o último Censo da Educação Superior (BRASIL, INEP, 2005) os dados demonstram que foram oferecidas, em 2004, 2.320.421 vagas, representando um aumento percentual de 15,8\% no ano, com relação ao anterior. Do total de vagas oferecidas, $87 \%$, que correspondem a 2.011.929, foram ofertadas pelas IES do setor privado; 5,7\% (131.675) pelas universidades estaduais; 5,3\% (123.959) pelas federais; e 2,3\% (52.858) pelas instituições municipais.

O número de inscrições para concorrer a essas vagas, naquele ano, atingiu o total de 5.053.992, sendo que 2.431.388 destas foram feitas em universidades públicas e $2.622 .604 \mathrm{em}$ IES particulares. A relação de candidato por vaga ficou em 2,2. Porém, nas instituições públicas, esse número atingiu 7,9 candidatos para uma vaga enquanto nas particulares ficou em 1,3. Entretanto, o número de ingressantes foi menor, atingindo o montante de 1.303 .110 (287.242 nas públicas e 1.015.868 nas particulares).

Constata-se, assim, uma capacidade ociosa de 43,8\%, correspondente a 1.017 .311 vagas não preenchidas na educação superior brasileira em 2004. Contudo, nas instituições federais, essa taxa foi de $0,9 \%$; nas estaduais $4,7 \%$; nas municipais $26,4 \%$; e nas instituições privadas $49,5 \%$. No que se refere aos concluintes, em 2004 houve um crescimento de $18,7 \%$ em relação a 2003: formaram-se 626.617 alunos nos cursos superiores brasileiros, sendo 202.262 nas IES públicas e 424.355 nas IES privadas.

$\mathrm{O}$ aumento da demanda por uma vaga na educação superior, aliado à baixa oferta na rede pública e à acelerada expansão do sistema privado provocaram uma mudança significativa nos últimos anos no cenário dos vestibulares no país, acirrando a competitividade entre as IES do setor privado. No caso das instituições particulares, a importância da imagem e da satisfação que os alunos sentem em fazer parte das mesmas vem se tornando um diferencial competitivo importante.

Neves e Ramos (2002, p.76) já consideravam essas mudanças em seus estudos, afirmando que se faz necessária uma atenção especial ao posicionamento das IES e à comunicação com o público: "independente do ramo, atividade ou porte, a organização, para sobreviver, deverá estar atenta a sua imagem".

De acordo com a revisão de literatura realizada, não foram encontrados muitos estudos empíricos que analisassem a imagem das IES, com base na percepção das pessoas. De acordo com Kazoleas, Kim e Moffitt (2001), muitas universidades preferem não dispor de informações que afetem sua posição estratégica e que poderiam revelar seus pontos fracos e fortes para seus concorrentes. Laundrum, Turrisi e Harless (1998) complementam essa análise sobre a escassez de estudos, afirmando que a publicação de trabalhos referentes à formação da imagem nas 
universidades pelos vários públicos é insuficiente, e que mais estudos são necessários abordando esse tema de pesquisa.

Kazoelas, Kim e Moffitt (2001) corroboram esse diagnóstico, afirmando ainda que, baseados em vários estudos teóricos em universidade, perceberam que a predominância das pesquisas sobre IES era sobre qualidade de ensino, mau gerenciamento financeiro e inadequação dos serviços oferecidos para a sociedade, mostrando que imagens positivas nem sempre são uma conclusão absolutamente previsível. Nesse sentido, de acordo com o levantamento realizado nos Encontros Anuais da Associação Nacional dos Programas de PósGraduação em Administração (EnANPAD), os temas de maior abrangência sobre as universidades brasileiras estão relacionados com expansão do ensino, satisfação, qualidade, formação do discente, gestão universitária e formação docente.

Diante desse quadro, pode-se inferir que as IES não podem ficar alheias à discussão. Em uma sociedade onde o conhecimento passou a ser um dos produtos mais valiosos e a preparação de pessoas um fator estratégico para as nações, as universidades passam a ocupar uma posição ainda mais relevante.

Considerando que a imagem corporativa constitui-se em vantagem competitiva e as instituições necessitam desenvolver uma imagem institucional adequada para atrair e manter alunos nos diversos cursos oferecidos, e ainda que a imagem positiva influência a satisfação e vice-versa, esta pesquisa, então, se propôs a investigar, por meio de um estudo empírico com estudantes de Administração de uma universidade de Santa Catarina, a associação entre as variáveis imagem e satisfação.

Assim, este estudo tem por objetivo geral analisar a satisfação dos alunos de Administração com o curso e demais serviços oferecidos, e a imagem corporativa de uma instituição de ensino superior (IES). Especificamente, a pesquisa identificou a avaliação dos alunos com relação aos atributos de satisfação com a universidade; levantou a percepção dos discentes sobre os atributos que compõem a imagem da IES; verificou se existem diferenças significativas na avaliação da imagem e da satisfação, considerando os dados de segmentação dos estudantes; analisou que componentes são considerados mais importantes na construção da imagem pelos alunos; e verificou se existe associação entre os componentes da imagem e da satisfação na percepção dos entrevistados.

Este trabalho encontra-se organizado da seguinte forma, além desta introdução: inicialmente, apresenta-se a fundamentação teórica que serviu de base para a pesquisa, a seguir descreve-se a metodologia utilizada, na seqüência são apresentados os principais resultados do estudo e finaliza-se com algumas considerações sobre o assunto, incluindo as limitações do trabalho e sugestões para futuras pesquisas.

\section{FUNDAMENTAÇÃO TEÓRICA}

Em Administração, os estudos sobre imagem e satisfação fazem parte da área de marketing e estão relacionados ao comportamento do consumidor. De acordo com Wilkie (1994), o comportamento do consumidor é uma atividade mental, emocional e física na qual as pessoas se engajam quando selecionam, compram, usam e descartam um produto ou serviço para satisfazer uma necessidade ou um desejo.

Autores como Boulding (1968), Moscovici (1978) e Morgan (2000) afirmam que a escolha do consumidor é influenciada pelas imagens que a pessoa possui sobre o serviço oferecido e o benefício que esse serviço lhes proporcionará. Portanto, o estudo sobre a imagem de determinada marca ou organização, na mente do consumidor, auxilia a compreensão de seu comportamento de compra e serve de base para a determinação de estratégias de marketing a serem desenvolvidas pelas organizações para atrair e manter clientes. Por essa razão, as universidades procuram se posicionar no mercado, utilizando estratégias de marketing bem 
definidas, com vistas à captação de estudantes e à redução da perda ou evasão de alunos, procurando satisfazê-los.

Dessa forma, torna-se importante entender o comportamento dos alunos, por meio da imagem que estes fazem da IES, o que permite identificar a maneira como decidem entre as alternativas de serviços e como avaliam esses serviços (satisfação), uma vez que os tenham recebido.

Muitas podem ser as definições de imagem, pois elas vêm sendo estudadas sob a perspectiva das mais diferentes áreas e sub-áreas do conhecimento, como semiótica, comunicação, filosofia, teologia, economia e marketing. Diante da revisão das diferentes formas de conceituar imagem, elaborados por autores como Reynolds e Gutman (1984), Kotler e Fox (1994), Kazoleas, Kim e Moffitt (2001), identifica-se que o seu conceito, numa perspectiva mercadológica, pode ser sintetizado como: representações, impressões, convicções e redes de significados de um objeto, produto, serviço, marca, organização ou loja, armazenados na memória do consumidor de forma holística. Essa impressão holística forma-se através de aspectos sensoriais, cognitivos, funcionais e afetivos.

Para De Toni, Milan e Schuler (2005), as imagens são capazes de influenciar e direcionar o comportamento das pessoas, sendo consideradas como um dos elementos intelectuais mais importantes para o ser humano. Entender as imagens e o que elas podem transmitir para o público consumidor constitui um importante aliado para a gestão estratégica das organizações, tornando-se, dessa forma, relevante aprofundar estudos nessa área.

Kazoleas, Kim e Moffitt (2001, p.04) acreditam que a imagem é "o resultado de um complexo processo, no qual a organização manda mensagens para seu público por meio de fatores sociais, históricos, experiências pessoais e fatores materiais". May (1974) complementa afirmando que a imagem se constitui de várias dimensões: algumas tangíveis, outras intangíveis; algumas mensuráveis, outras não; algumas significantes, ou não-significantes; algumas mutáveis, outras imutáveis.

A imagem é formada, portanto, por um conjunto de fatores tangíveis (funcionais) e intangíveis (cognitivos, simbólicos e emocionais) que o homem percebe no meio onde vive. Uma instituição de ensino superior, por exemplo, é avaliada por sua infra-estrutura, qualidade do ensino, competência do seu corpo docente, funcionários, laboratórios, localização, reputação, entre outros aspectos. A imagem que o aluno terá da universidade dependerá do que o mesmo percebe e vê nos atributos citados.

Numa perspectiva mercadológica, Barich e Kotler (1991) afirmam que a imagem apresenta-se sob quatro tipos: imagem da marca (como as pessoas percebem uma marca particular em relação às suas concorrentes); imagem dos produtos (como as pessoas vêem uma determinada categoria de produtos); imagem de marketing (a forma como é vista a qualidade da oferta e mix de marketing da organização) e a imagem corporativa (como as pessoas percebem a empresa num todo). No contexto desta pesquisa, o foco de estudo recaiu na imagem corporativa que, segundo Melo e Vieira (2004, p.01), "representa as impressões e opiniões recentes acerca de uma firma, sintetizando um conjunto complexo de significados que influenciam comportamentos e a tomada de decisão".

De acordo com estudos realizados sobre imagem em universidades, o que se percebe é que uma imagem corporativa consistente também é necessária para essas organizações, principalmente no ambiente competitivo em que o mercado das IES está vivendo. Segundo o trabalho de Canopf, Ichikawa e Festinalli (2003), que propõe uma reflexão acerca do ensino superior, a partir da expansão acelerada do número de instituições e cursos de graduação em Administração na região Sudoeste do Paraná, observa-se que a expansão do ensino superior não é um caso isolado de IES de algumas regiões, e sim uma preocupação de todas as universidades. Com base nas conclusões dos autores citados, é possível afirmar que a localização da instituição, o conceito obtido pelos cursos, a titulação do corpo docente e o valor 
das mensalidades praticadas são fatores que influenciarão a decisão do acadêmico sobre onde estudar e formarão a imagem que o aluno fará da instituição.

Dutra, Oliveira e Gouveia (2003), analisam a qualidade do serviço oferecido numa universidade e confirmam que, de acordo com os discentes, a qualidade do serviço educacional é fortemente influenciada por quatro das trinta e cinco variáveis apresentadas no trabalho, quais sejam: o desempenho dos funcionários administrativos, a preocupação com a praticidade do conhecimento, o preparo dos professores e o intercâmbio entre o mercado e a instituição de ensino. São esses fatores que, se bem administrados, irão formar um serviço de qualidade a ser oferecido pela instituição e, juntamente com outros atributos, contribuirão para a construção da imagem geral da IES.

Kazoelas, Kim e Moffitt (2001) apontam, baseados em vários estudos teóricos internacionais sobre universidade, que a predominância nesses trabalhos reside em questões relativas ao ensino, à inadequação dos serviços das instituições e ao mau gerenciamento financeiro. Palácio, Meneses e Perez (2002) acreditam, no entanto, que apesar dos poucos artigos publicados sobre imagem, destacam-se os estudos que têm tentado analisar a imagem e seu processo de formação na perspectiva do receptor. Portanto, este trabalho procura focalizar o estudo nessa mesma perspectiva, contribuindo para o entendimento do comportamento do discente como consumidor dos serviços educacionais.

Se bem que os estudos sobre imagem de IES sejam raros, a satisfação dos clientes, no entanto, é tema em evidência permanente, tendo sido foco de análise em pesquisas e assunto de publicações acadêmicas. Pesquisadores como Rossi e Slongo (1997), Farias e Santos (1998), Urdan e Rodrigues (1998), Marchetti e Prado (2001) são alguns exemplos brasileiros.

Kotler (1998) ressalta que a necessidade de se manter os consumidores satisfeitos é pressuposto central para as organizações, pois, o custo de atrair novos consumidores é maior do que o custo de manter clientes antigos. Sendo assim, a importância do assunto, na opinião de Anderson, Fornell \& Lehmann (1994), reside no fator de que a satisfação do consumidor tem sido bastante reconhecida como assunto relevante no ambiente acadêmico, e também como um objetivo constitutivo da atividade empresarial.

Outros benefícios, confirmados na literatura que aborda o tema satisfação de clientes, evidenciam que níveis mais elevados de satisfação levam à maior retenção e lealdade desses clientes e que, com o aumento da lealdade, a satisfação do consumidor pode ajudar a assegurar receitas no longo do tempo, a reduzir custos de transações futuras, a diminuir a elasticidade de preços e a minimizar a probabilidade de os clientes trocarem de fornecedor caso haja uma queda no nível da qualidade, como sugerem Anderson, Fornell e Rust (1997); Anderson (1998) e Anderson e Fornell (1994).

No estudo de Palácio, Meneses e Perez (2002), os autores consideraram que a satisfação é uma resposta afetiva em determinado tempo, e é determinada pelas expectativas dos estudantes quando entram na universidade. Relatam ainda que a relação entre a satisfação do cliente e a imagem corporativa não tem sido muito estudada na literatura.

Complementando os estudos sobre imagem e satisfação, Nguyen e Leblanc (2001) citam que esta última tem um efeito direto e significante na imagem corporativa, ou seja, alto nível de satisfação do consumidor implica uma imagem corporativa positiva por parte deste.

Como os componentes cognitivos e afetivos fazem parte dos aspectos que compõem a imagem formada por um indivíduo, conforme observado na pesquisa de Palácio, Meneses e Peres (2002), foram propostas as seguintes hipóteses nulas do trabalho: H01 - os componentes cognitivos da imagem não são associados à satisfação; H02 - os componentes afetivos da imagem não são associados à satisfação; H03 - a imagem percebida pelos discentes de uma universidade independe da sua satisfação.

Apresentam-se no Quadro 1 as hipóteses do estudo e os autores que as fundamentam. 


\begin{tabular}{|c|c|}
\hline Hipótese & Autores \\
\hline $\begin{array}{l}\text { Ho1 - Os componentes cognitivos da imagem } \\
\text { não são associados à satisfação; }\end{array}$ & $\begin{array}{l}\text { Baloglu e Brinberg (1997); - Canopf, Ichikawa e Festinalli } \\
\text { (2003); Damásio (2001); Davidoff (2001); Dichter (1985); } \\
\text { Johnson-Laird (1990); Kazoleas, Kim e Moffitt (2001); } \\
\text { Kosslyn (1996); Lemos (2002); Lévy(1993); Maslow (1952); } \\
\text { Neves (2000); Neves e Ramos (2002); Nicolao e Espartel } \\
\text { (2004); Palácio, Meneses e Perez (2002); Rodríguez (1996); } \\
\text { Schacter (1996); Schiffman e Kanuk (2000); Schuler e De } \\
\text { Toni (2004); Shapiro e Krishnan (2001); Souki e Pereira } \\
\text { (2004); Sternberg (2000); Stillings (1995). }\end{array}$ \\
\hline $\begin{array}{l}\text { Ho2 - Os componentes afetivos da imagem não } \\
\text { são associados à satisfação; }\end{array}$ & $\begin{array}{l}\text { - Baloglu e Brinberg (1997); Dichter (1985); Goleman (1995); } \\
\text { Kennedy (1977); Ledoux (2001); Mazursky e Jacoby (1986); } \\
\text { Nicolao e Espartel (2004); Palácio, Meneses e Perez (2002); } \\
\text { Reynolds e Gutman (1984). }\end{array}$ \\
\hline $\begin{array}{l}\text { Ho3 - A imagem percebida pelos discentes de } \\
\text { uma universidade independe da sua satisfação. }\end{array}$ & $\begin{array}{l}\text { - Barich e Kotler (1991); Beulke (1998); Kazoleas, Kim e } \\
\text { Moffitt (2001); Kotler (1998); Loundon e Della Bitta (1995); } \\
\text { May (1974); Melo e Vieira (2004); Nguyen e Leblanc (2001); } \\
\text { Nicolao E Espartel (2004); Palácio, Meneses e Perez (2002); } \\
\text { Parameswaran e Glowacka (1995); Souki e Pereira (2004). }\end{array}$ \\
\hline
\end{tabular}

Quadro 1 - Autores que fundamentam as hipóteses do estudo

\section{METODOLOGIA}

Este estudo foi orientado pelo paradigma positivista, o qual, de acordo com Triviños (1987, p.36), "não aceita outra realidade que não sejam os fatos, fatos que possam ser observados". Segundo esse paradigma, os estudos, para serem considerados ciência, devem recair sobre fatos conhecidos, que se realizem e que sejam passíveis de observação.

Desta forma, para alcance dos objetivos propostos neste trabalho, realizou-se um levantamento de caráter exploratório-descritivo, com o universo de 2842 alunos, dos cursos de Administração, distribuídos pelos cinco campi da universidade, matriculados no segundo semestre letivo de 2005. A pesquisa foi aplicada aos estudantes em sala de aula, resultando numa amostra de 1536 respondentes.

A imagem e a satisfação dos alunos foram analisadas de acordo com a fundamentação teórica apresentada. A base principal para este estudo foi o trabalho realizado por Palácio, Meneses e Perez (2002) junto aos discentes em uma universidade espanhola. De todos os atributos analisados por esses autores foram escolhidos aqueles que, na revisão da literatura, também foram citados em outras pesquisas.

No questionário, foram incluídas 37 variáveis que são comuns para medir a imagem e a satisfação dos estudantes. As variáveis de análise estão agrupadas em blocos, formando construtos. Os blocos designados com letra de A até E avaliam os aspectos cognitivos e o Bloco F os aspectos afetivos da imagem, conforme se apresentam no Quadro 2.

\begin{tabular}{|l|}
\hline \multicolumn{1}{|c|}{ Variáveis analisadas } \\
\hline Bloco A - Características Gerais \\
\hline A1 - Facilidade de ingresso na universidade \\
\hline A2 - Localização do campus \\
\hline A3 - Tamanho da instituição \\
\hline A4 - Valor da mensalidade \\
\hline A5 - Universidade avançada perante seus concorrentes \\
\hline A6 - Propagandas da instituição \\
\hline A7 - Adequação das propagandas da universidade \\
\hline A8 - Não precisa prestar vários vestibulares \\
\hline A9 - Reputação da instituição \\
\hline
\end{tabular}




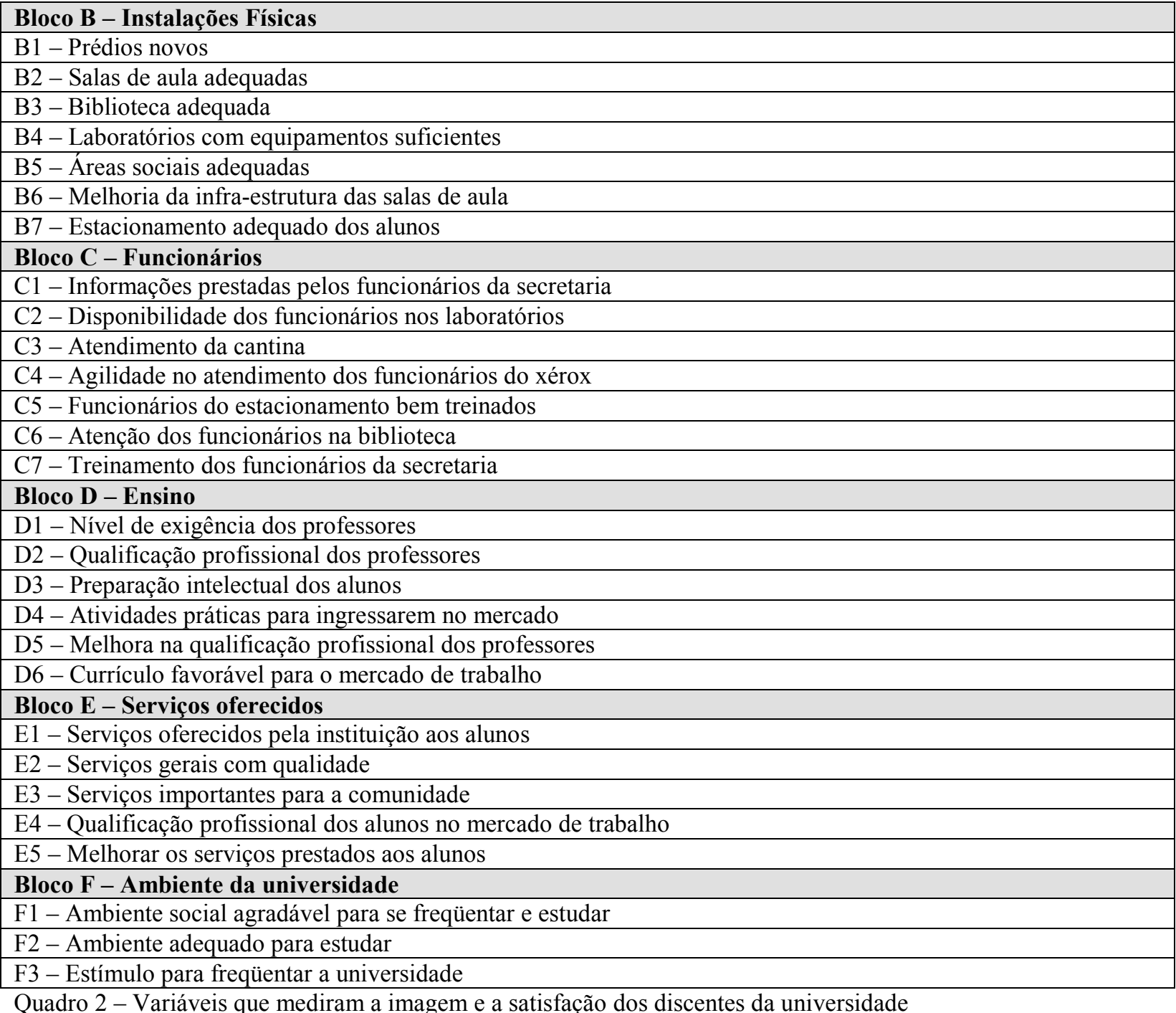

Utilizaram-se também duas variáveis específicas para medir a imagem geral da universidade e cinco para avaliar a imagem dos concorrentes, como mostra o Quadro 3.

\section{Imagem geral da universidade}

\section{Variáveis analisadas}

P1 - Imagem geral da universidade antes do vestibular

P2 - Imagem geral da universidade depois do vestibular

Bloco $\mathbf{H}$ - Imagem das universidades concorrentes

H1 - Universidade B

$\mathrm{H} 2$ - Universidade $\mathrm{C}$

$\mathrm{H} 3$ - Universidade D

$\mathrm{H} 4$ - Universidade $\mathrm{E}$

H5 - Universidade F

Quadro 3 - Variáveis que mediram a imagem geral dos discentes relativa à universidade Quadro 4.

A satisfação geral também foi medida por mais 10 variáveis, como se observa no 


\begin{tabular}{|l|}
\hline \multicolumn{1}{|c|}{ Variáveis analisadas } \\
\hline Bloco G - Satisfação Geral \\
\hline G1 - Satisfação geral com a universidade \\
\hline G2 - Universidade melhor do que esperava \\
\hline G3 - Facilidade de solucionar um problema \\
\hline G4 - Inserção no mercado de trabalho \\
\hline G5 - Preferência das empresas por profissionais formados pela IES \\
\hline G6 - Qualidade do ensino que recebe \\
\hline G7 - Nível de formação profissional satisfatório \\
\hline G8 - Mudanças no ensino implantadas \\
\hline G9 - Comprometimento efetivo dos professores com a qualidade do curso \\
\hline G10 - Instituição como universidade ideal \\
Quadro 4 - Variáveis que mediram satisfação geral dos discentes com a universidade.
\end{tabular}

As variáveis que mediam a imagem (nos Blocos $\mathrm{A}$ até $\mathrm{F}$ ) e a satisfação geral (no Bloco G) foram transformadas em afirmativas e avaliadas por meio de uma escala de seis pontos do tipo "concordo-discordo", acompanhando o trabalho de Palácio, Meneses e Perez (2002), que utilizaram esse tipo de escala para medir tanto a imagem quanto à satisfação geral dos pesquisados. Optou-se pela escala de 6 pontos para tentar evitar o erro de tendência central. $\mathrm{O}$ aluno tinha que atribuir uma nota, conforme o grau de concordância com essas afirmativas, o que resultava em uma imagem mais positiva ou mais negativa sobre cada atributo.

Segundo Malhotra (2001), essa escala de pontuação é amplamente utilizada, e requer que os respondentes indiquem o grau de concordância e discordância em relação a uma série de afirmações. A construção dessa escala envolve a elaboração inicial de um extenso conjunto de afirmações que reflitam a qualidade ou características do objeto de estudo que possivelmente influenciem a atitude da pessoa em relação a esse objeto (CHURCHILL, 1991). O refinamento da escala é feito de forma a manter apenas as afirmações com maior capacidade de discriminar entre atitudes favoráveis e desfavoráveis. Quanto maior for o número de categorias melhor é a discriminação possível entre objetos. Porém, como a maioria dos respondentes não consegue lidar com muitas categorias, diretrizes tradicionais sugerem que o número apropriado de categorias em uma escala deve ser sete, com uma variação de dois pontos para mais ou para menos. Assim, esse tipo de escala pode conter um total de cinco a nove pontos, o que justifica a escala de 6 pontos utilizada neste trabalho. (MALHOTRA, 2001).

As variáveis que mediam a imagem geral da universidade (questões P1 e P2) e a satisfação (Blocos de A até F) foram avaliadas por uma escala de 10 pontos, cujo objetivo era facilitar a análise por parte dos alunos, de vez que os mesmos também costumam ser avaliados pela mesma escala nas disciplinas.

Os dados coletados na pesquisa de campo, foram tabuladas e apresentados em tabelas de distribuição de freqüência com as médias e desvio-padrão de cada variável analisada. Posteriormente foi feito o cruzamento entre as variáveis do estudo, cujos resultados foram apresentados em forma de médias expostas em tabelas, ora respeitando a segmentação inicial do questionário, ora reunindo segmentos como forma de possibilitar melhor comparação da amostra.

Visando a averiguar se as diferenças existentes entre as médias eram estatisticamente significativas, realizou-se uma análise de variância ANOVA. De acordo com Malhotra (2001), esse teste é aplicado para estudar as diferenças entre as médias de duas ou mais populações. Nas comparações a posteriori foi feito o teste de Tukey para números desiguais de repetições, objetivando detalhar os dados identificados no teste anterior, possibilitando uma maior identificação da diferença da significância entre as médias. O software utilizado nesse processo foi o STATISTICA versão 6.0. 
A partir da organização das informações e apresentação das tabelas foi possível analisar como os alunos de Administração e suas ênfases avaliam a imagem que têm da universidade estudada e sua satisfação com ela. Como resultados, foram estabelecidas as características dos estudantes em cada bloco de análise, mostrando como se apresentam a imagem e a satisfação dos acadêmicos relativamente à IES. Para complementar a avaliação dos resultados, foi realizada a análise multivariada dos dados, que tem por objetivo o estudo de duas ou mais variáveis simultaneamente (VOLLE, 1985). Na visão de Escofier e Pagès (1992), os métodos multivariados de análise têm comprovado sua eficácia nos estudo de grandes massas de informações. Essa análise permite utilizar a percepção para analisar os gráficos, pois, no sentido literal do termo, se vêem "com os olhos" os agrupamentos, oposições e tendências, impossíveis de se discernir diretamente sobre uma grande tabela de números, inclusive depois de um exame prolongado (ESCOFIER e PAGÈS, 1992).

Foi utilizada neste trabalho a Análise Fatorial de Correspondência Múltipla (AFCM), que permitiu obter uma visão melhor da situação-problema de pesquisa pela verificação simultânea das variáveis. A projeção de todas as variáveis e indivíduos no mesmo plano fatorial possibilitou interpretar a situação da imagem e da satisfação dos alunos pesquisados. Para essa avaliação foram considerados somente os indivíduos que responderam a todas as perguntas do questionário, o que resultou em uma amostra de 600 alunos respondentes. O objetivo dessa redução de dados é conseguir aprofundar as informações e chegar a resultados mais precisos, deixando os gráficos mais claros e objetivos.

O software estatístico utilizado na Análise Fatorial de Correspondência Múltipla foi o SPAD versão 3.5 em virtude de conter todos os métodos de análise exploratória de dados simples e miltidimensionais necessários para este trabalho.

\section{RESULTADOS}

A amostra final, constituída de 1536 alunos de administração, dos cinco campi que compõem a IES analisada, apresentavam as seguintes características: $51,5 \%$ eram do sexo feminino, $72 \%$ situavam-se na faixa etária de até 24 anos e $64 \%$ possuíam renda familiar mensal R\$3.000,00 ou menos.

Com relação à satisfação geral dos estudantes entrevistados, as médias variaram entre 3,12 (facilidade de solucionar um problema) e 3,96 (comprometimento dos professores com a qualidade do curso), em uma escala de seis pontos, revelando uma satisfação apenas regular. Detalhando a análise da satisfação dos estudantes, por construtos, verificou-se que as médias variaram entre 4,42 e 7,67, em uma escala de dez pontos, o que se constitui em um resultado apenas mediano, insuficiente para o ambiente competitivo que ora se apresenta no ensino superior brasileiro.

A satisfação dos alunos com as características gerais da IES situou-se entre as médias 5,0 e 7,67 em uma escala de 10 pontos; a relacionada às instalações físicas, entre 4,42 e 6,84; a relativa aos funcionários, entre 6,05 e 7,24; a que diz respeito ao ensino, entre 5,50 e 7,52; a satisfação com os serviços, entre 5,84 e 6,91 e a que se relaciona ao ambiente da universidade ficou entre 6,30 a 7,07.

$\mathrm{Na}$ análise da satisfação por variáveis específicas, receberam as piores avaliações: o estacionamento (com média 4,42); o valor das mensalidades $(5,0)$; a suficiência de equipamentos nos laboratórios de informática $(4,84)$; a adequação das salas de aulas $(5,5)$; as atividades práticas $(5,5)$; e os serviços oferecidos aos alunos $(5,84)$. Receberam as melhores avaliações: o tamanho da instituição $(7,67)$; a localização do campus $(7,61)$ e a qualificação profissional dos professores $(7,52)$.

Conforme mencionado na fundamentação teórica, de acordo com Anderson, Fornell e Rust (1997), Anderson (1998) e Anderson e Fornell (1999), níveis mais elevados de satisfação 
levam a maior retenção e lealdade de clientes, contribuindo para assegurar receitas ao longo do tempo e reduzir a probabilidade de clientes trocarem de fornecedor. Portanto, é necessário que as instituições de ensino superior procurem garantir um alto índice de satisfação entre seus alunos para que possam obter maior competitividade em ambientes de alta concorrência.

No que diz respeito à imagem da IES, os resultados evidenciaram que nenhuma variável que compõe a imagem corporativa destacou-se positivamente de forma expressiva, pois as médias das avaliações variaram entre 2,68 e 4,95 numa escala de seis pontos, revelando uma imagem de nível apenas regular. Evidenciou-se, nos resultados referentes à imagem geral da instituição, que a imagem que os estudantes faziam da universidade antes de ingressarem na mesma (média 7,73 em uma escala de 10 pontos) era melhor do que a imagem formada depois do ingresso (média 6,40), demonstrando que, quando o aluno entra em contato com o serviço educacional oferecido, a imagem piora. Esse último resultado confirma aquele obtido por Palácio, Menezes e Perez (2002).

Os dados da pesquisa indicam a necessidade de maior atenção da IES com relação à sua imagem, pois Melo e Vieira (2004) propõem o fortalecimento da imagem corporativa como uma ferramenta estratégica fundamental, que gerará maior competitividade. Essa competitividade possibilita a atração de novos clientes e fortalece a lealdade dos já existentes. Autores como Boulding (1968), Moscovici (1978) e Morgan (2000) afirmam que a escolha do consumidor é influenciada pela imagem que a pessoa possui sobre o serviço oferecido e o benefício que esse serviço lhes proporcionará. No caso de uma IES, uma imagem satisfatória, além de ajudar a atrair novos alunos, reduzirá a evasão escolar e contribuirá para que o egresso retorne à universidade para fazer novos cursos de pós-graduação. Isso porque, segundo Kotler (1998), o custo de atrair novos consumidores é maior do que o custo de manter os antigos.

A análise cruzada dos dados revelou alguns aspectos que merecem ser destacados: a) os estudantes com renda familiar mais baixa possuem melhor imagem da instituição; b) à medida que os alunos ficam mais tempo no curso e precisam usar os laboratórios de informática, piora a imagem dos discentes em relação à suficiência dos equipamentos disponíveis; e c) quanto mais tempo os estudantes permanecem na universidade, mais críticos eles ficam, reduzindo a imagem da universidade com relação à quantidade de atividades práticas para ingressarem no mercado de trabalho.

Esses dados trazem algumas implicações para as estratégias de marketing da instituição. Se o mercado-alvo da universidade for os alunos de renda mais baixa, é preciso oferecer mais "valor" pelo preço cobrado, melhorando o custo-benefício dos serviços oferecidos, principalmente naquelas variáveis que mais contribuíram para a imagem e a satisfação e que receberam baixa ou média avaliação. Se o objetivo da instituição for atrair alunos de maior poder aquisitivo, com a finalidade de aumentar o valor das mensalidades ou reduzir a inadimplência, também é necessário aperfeiçoar os serviços oferecidos antes de direcionar suas estratégias de comunicação para atrair potenciais estudantes de rendas mais altas, pois os resultados da pesquisa mostram que quanto mais alta é a renda, pior é a imagem e menor a satisfação com a instituição, ou seja, o nível de exigência é maior.

A Análise Fatorial de Correspondência Múltipla - AFCM permitiu identificar as seguintes variáveis que mais contribuíram para a formação da satisfação dos discentes de Administração e da imagem da universidade pesquisada: 1) reputação da IES; 2) preparação intelectual dos estudantes para ingressarem no mercado de trabalho, 3) qualidade dos serviços, 4) áreas sociais adequadas para os alunos; 5) disposição dos funcionários dos laboratórios em ajudar e 6) estímulo para os alunos em freqüentar a universidade, consideradas as mais importantes pelos entrevistados. As cinco primeiras variáveis estão relacionadas com os componentes cognitivos e a última com o componente afetivo da imagem e da satisfação.

Fazendo uma relação desses resultados com o trabalho realizado na Espanha, por Palácio, Meneses e Perez (2001), foram observadas algumas semelhanças. Segundo os autores 

DA IES

citados, os cinco fatores cognitivos que, na opinião dos alunos entrevistados, mais contribuíram para a formação da imagem foram: a preparação e orientação dos estudantes para o mercado de trabalho, a reputação da IES, o número de alunos na universidade, a facilidade de ingresso na instituição e a idade da universidade.

Já a pesquisa de Dutra, Oliveira e Gouveia (2003), citada na teoria que fundamentou esse trabalho, mostrou que a qualidade do serviço educacional em uma universidade é influenciada pelo desempenho dos funcionários administrativos, a preocupação com a praticidade do conhecimento, o preparo dos professores e o intercâmbio entre o mercado e a IES. Como se percebe, seja no Brasil ou no Exterior, os alunos centram suas preocupações na preparação para o mercado de trabalho e na reputação da instituição.

As análises realizadas a partir dos resultados deste estudo permitiram testar duas hipóteses do trabalho: H-01, que afirma que os componentes cognitivos da imagem não são associados à satisfação e $\mathrm{H}-02$, que declara que os componentes afetivos da imagem não são associados à satisfação. Exemplificando-as no plano fatorial, pode-se observar na Figura 01 que existe uma associação entre a imagem e a satisfação. Os círculos mais claros correspondem à imagem e os escuros à satisfação.

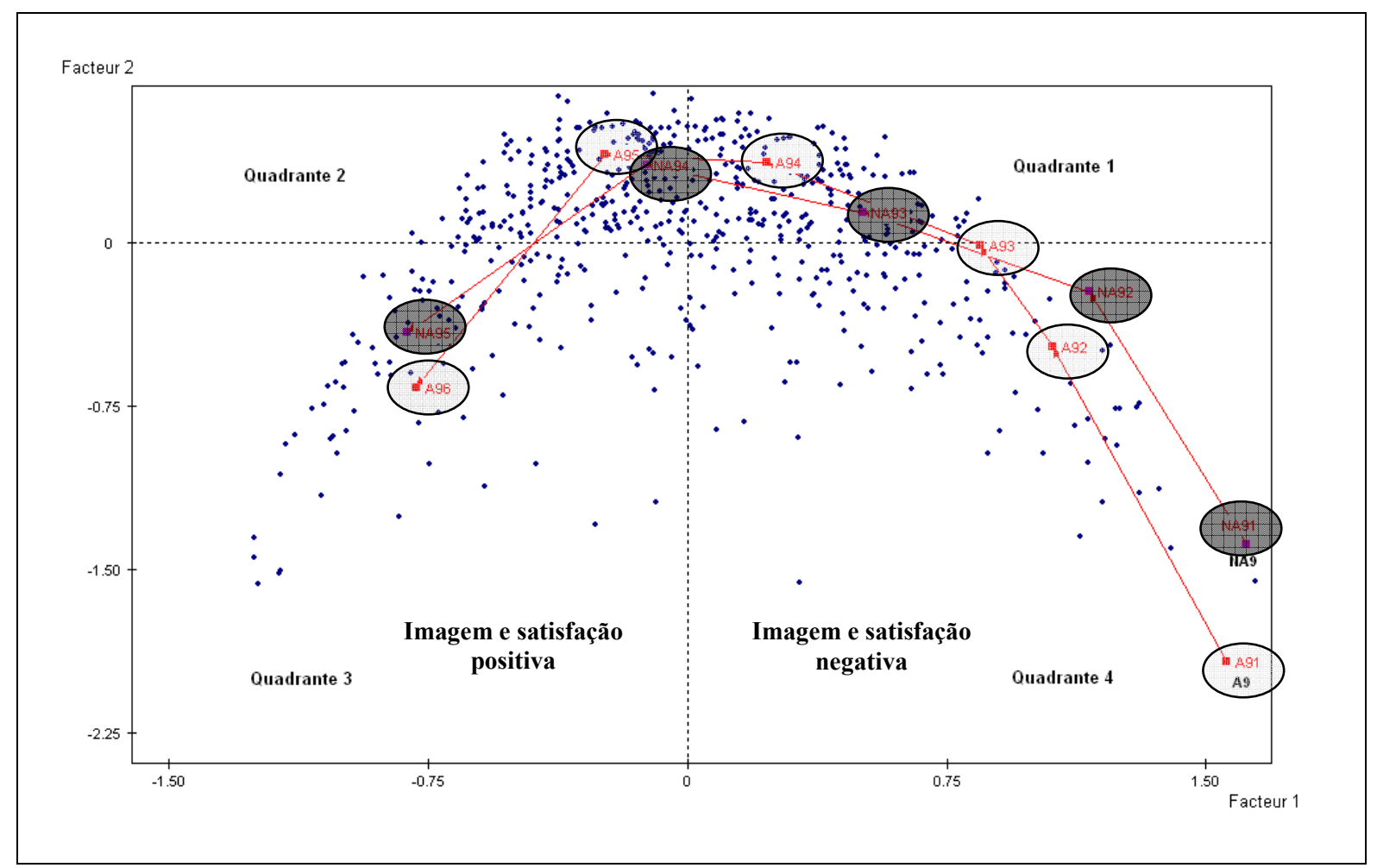

Figura 01 - Plano fatorial analisado correspondente à reputação da instituição

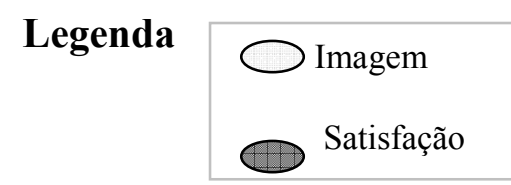

O quadrante 3 expõe a imagem e satisfação positiva (modalidade 5 e 6 ) e o quadrante 4 a negativa (modalidades 1, 2 e 3). Entende-se, portanto, que quando o aluno tem uma boa imagem da reputação da instituição, também tem uma satisfação positiva; quando negativa a imagem, a satisfação também é ruim, pois os pontos tanto da imagem quanto da satisfação encontram-se no quadrante 4. 
Para confirmar os dados acima expostos foi realizado o teste de associação quiquadrado $\left(\mathrm{X}^{2}\right)$. Esse teste permite averiguar que existe associação entre as variáveis imagem e satisfação na população em estudo, pois o valor do qui-quadrado calculado $(1606,82)$ é maior que o qui-quadrado tabelado $(61,66)$, tendo como índice de grau de liberdade 45 e um nível de significância de 0,05 , indicando existir associação entre a satisfação e a imagem, isto é, quando o aluno tem uma alta imagem da universidade também apresenta elevada satisfação com a instituição. As demais variáveis também evidenciaram essa associação, rejeitando as duas hipóteses nulas, e conseqüentemente aceitando as hipóteses alternativas que afirmam que os componentes cognitivos e afetivos da imagem estão associados à satisfação.

Nos resultados obtidos, das 37 variáveis que mediam simultaneamente a imagem e a satisfação, 25 apresentaram associação nas respostas, o que corresponde a 67,57\% do total. Destas últimas, 18 mostraram concomitantemente imagem e satisfação regular, totalizando $72 \%$ das respostas. Com esse resultado pode-se rejeitar a terceira hipótese nula do estudo, a qual afirma que a imagem percebida pelos discentes de uma universidade independe da sua satisfação. Como os dados demonstraram, a imagem dos alunos da universidade em questão depende da satisfação.

\section{CONSIDERAÇÕES FINAIS}

Estudos realizados em diferentes contextos vêm demonstrando que a imagem de uma marca influencia o comportamento do consumidor por um produto ou serviço e que a imagem corporativa exerce influência na decisão das pessoas em estabelecer contato com determinada organização, quer seja do setor privado ou do setor que não visa ao lucro.

A imagem corporativa de uma IES é composta por diversos construtos subdivididos em um número expressivo de variáveis que, em conjunto, formam a imagem geral que as pessoas fazem de uma organização.

No contexto da prestação de serviços educacionais, observa-se a necessidade de as instituições de ensino superior desenvolverem uma imagem específica, de prestígio ou qualidade, que as diferencie de suas concorrentes, a fim de manter sua competitividade no mercado. Por essa razão, realizou-se esta pesquisa para analisar a imagem corporativa e a satisfação dos alunos de uma IES de Santa Catarina.

Os resultados do estudo mostraram que existem diferenças significativas entre as percepções de imagem e satisfação quando os alunos foram segmentados por variáveis sóciodemográficas, e demonstrou que a imagem percebida pelos alunos de Administração da universidade pesquisada depende de sua satisfação com o curso e demais serviços oferecidos.

Essas evidências poderão auxiliar o novo posicionamento do curso de Administração da IES, no mercado, frente ao cenário competitivo que as IES estão enfrentando, atualmente, à medida que indica as variáveis que precisam ser aperfeiçoadas a fim de melhorar a satisfação dos alunos com os serviços educacionais oferecidos e a imagem corporativa da instituição.

A realização desta pesquisa resultou também em alguns aspectos que precisam ser mencionados: apresenta uma contribuição importante para o avanço da ciência administrativa, na área de marketing, ao aplicar teorias já desenvolvidas sobre o tema, para o conhecimento da realidade organizacional no contexto brasileiro; relaciona o estudo de imagem com satisfação, na prestação de serviços educacionais, assunto ainda pouco explorado no país; mostra a existência de associação entre a imagem corporativa e a satisfação do usuário em um serviço importante para a sociedade, que é a educação; e fornece subsídios para a instituição desenvolver suas estratégias de marketing educacional, com base em pesquisas acadêmicas, possibilitando o posicionamento da IES no mercado, a melhoria da qualidade dos serviços oferecidos e o aprimoramento da imagem corporativa da organização. 
Como limitações do estudo pode-se destacar o fato de apenas parte do universo de alunos ter respondido ao questionário, por diversas razões, como falta às aulas nos dias de aplicação dos questionários, desistência do curso, sem trancamento formal de matrícula ou simples recusa em participar da pesquisa. Embora o tamanho da amostra final tenha sido satisfatório, é possível que a porcentagem de não respondentes $(45,95 \%)$ pudesse alterar os resultados aqui apresentados. Outro fator limitante diz respeito ao fato de o estudo ter sido realizado em apenas uma IES de determinada região, não podendo os seus resultados ser generalizados para outras universidades ou demais regiões geográficas do país, onde os contextos são provavelmente diferentes.

Para a realização de futuras investigações, sugere-se: estender o estudo de imagem e satisfação para outros cursos de graduação e pós-graduação da mesma IES analisada; desenvolver pesquisa com os egressos para poder comparar com os resultados obtidos e verificar as similaridades e divergências entre os dois trabalhos; realizar estudo com os outros públicos internos da IES, como professores, pesquisadores e funcionários administrativos; colher a percepção de outros atores envolvidos com o processo de formação de profissionais, como os dirigentes de organizações que empregam os administradores formados pela universidade em questão; e expandir a pesquisa para outras universidades do estado de Santa Catarina, assim como para outras regiões do país.

O estudo revelou também, que a pesquisa acadêmica, mesmo com suas limitações, é um poderoso instrumento a ser utilizado no conhecimento de uma realidade, ao se constituir em ponto de partida para a implementação de mudanças planejadas.

\section{REFERÊNCIAS}

ANDERSON, E. W. Customer satisfaction and Word-of-mouth. NQRC (National Quality Research Center): The University of Michigan, 1998.

ANDERSON, E. W.; FORNELL, C. A customer satisfaction research prospectus. In: RUST, R. T.; OLIVER, R. L. (eds.). Service quality: new directions in theory and practice. Thousand Oaks: Sage Publications, p.241-68, 1994. Disponível em: <http:// www.periodicos.capes.gov.br>. Acesso em: 28 outubro 2004.

The customer satisfaction index as a leading indicator. In: IACOBUCCI, D.; SWARTZ, T. (eds.). Handbook of services marketing and management. New York: Sage Publications, 1999. Disponível em: <http:// www.periodicos.capes.gov.br>. Acesso em: 27 setembro 2004.

ANDERSON, E. W.; FORNELL, C.; LEHMANN, D. R. Customer satisfaction, market share, and profitability: findings from Swedwn. Journal of Marketing, Chicago, IL, v.58, n.3, p.5366, 1994. Disponível em: <http:// www.periodicos.capes.gov.br> Acesso em: 28 outubro 2004.

ANDERSON, E. W.;FORNELL, C.; RUST, R. T. Customer satisfaction, productivity and profability: differences between goods and services. Marketing Science, v.16, n.2, p.129-45, 1997. Disponível em: <http:// www.periodicos.capes.gov.br>. Acesso em: 28 outubro 2004.

BALOGLU, S.; BRINBERG, D. Affective image of turism destinations. Journal of Travel Research. V.35, n.4, p.11-15, 1997. Disponível em: <http:// www.periodicos.capes.gov.br>. Acesso em: 28 outubro 2004. 
BARICH, H.; KOTLER, P. A framework for marketing image management. Slon Management Review. Winter, 1991, p. 97-104. Disponível em: <http:// www.periodicos.capes.gov.br>. Acesso em: 28 outubro 2004.

BEULKE, M. Pesquisa de Satisfação de Clientes: um estudo no setor de TV por assinatura no mercado de Porto Alegre. In: ENCONTRO ANUAL DA ANPAD, 22., 1998, Foz do Iguaçu. Anais eletrônicos... Foz do Iguaçu: ANPAD 1998. Disponível em: $<$ http://www.anpad.org.br>. Acesso em: 20 de dezembro 2004.

BOULDING, K. E. The image. $6^{\text {a }}$ printing Michigan: Ann Arbor Paperback, 1968.

BRASIL. Ministério da Educação. Instituto Nacional de Estudos e Pesquisas Educacionais Anísio Teixeira - INEP. Censo da Educação Superior 2004 indica um aumento na eficiência das instituições Federais. Brasília, 16 de dezembro de 2004. Disponível em: $<$ http:// www.inep.gov.br>. Acesso em: 01 setembro 2005.

CANOPF, L.; ICHIKAWA, E. Y.; FESTINALLI, R. C. A expansão do ensino superior em Administração no sudoeste do Paraná: reflexões introdutórias. In: ENCONTRO ANUAL DA ANPAD, 27., 2003, Atibaia. Anais... Atibaia: ANPAD, 2003.

CHURCHILL, G. A. Marketing Research: methodological foundations. Fort Worth. The Dryden Press, 1991.

DAMÁSIO, A. R. O mistério da consciência. São Paulo: Cia das Letras, 2001.

DAVIDOFF, L. L. Introdução à psicologia. São Paulo: Cia das Letras, 2001.

DE TONI, D.; MILAN, G. S.; SCHULER, M. Configuração de imagens de serviços: um estudo aplicado aos serviços de fisioterapia disponibilizados por um plano de saúde. In: ENCONTRO ANUAL DA ANPAD, 24., 2005, Brasília. Anais... Campinas: ANPAD, 2005.

DICHTER, E. What's in an image. Journal of Consumer Marketing. V.2, n.1, p.75-81, 1985. Disponível em: <http:// www.periodicos.capes.gov.br>. Acesso em: 26 novembro 2004.

DUTRA, H. F. O.; OLIVEIRA, P. A.; GOUVEIA, T. B. Avaliando a qualidade de serviço numa Instituição de Ensino Superior. In: ENCONTRO ANUAL DA ANPAD, 26., 2003, Salvador. Anais... Salvador: ANPAD 2002.

ESCOFIER, B.; PAGÈS, J. Análisis factoriales simples y múltiples: objetivos, métodos e interpretación. Bilbao : Ed. Universidad Del Pais Vasco, 1992.

FARIAS, S. A.; SANTOS, R. C. Atributos de satisfação nos serviços de hotelaria: uma perspectiva no segmento de terceira idade. In: ENCONTRO ANUAL DA ANPAD, 22., 1998, Foz do Iguaçú. Anais.... Foz do Iguaçu: ANPAD, 1998.

GOLEMAN, D. Inteligência emocional: a teoria revolucionária que redefine o que é ser inteligente. Rio de Janeiro: Objetiva, 1995. 
JOHNSON-LAIRD, P. N. Mental models. Fundations of cognitive science. London: The MIT Press, 1990. Disponível em : <http:// www.periodicos.capes.gov.br $>$. Acesso em: 28 outubro 2004

KAZOLEAS, D.; KIM, Y.; MOFFITT, M. A. Institutional image: A case study. Corporate Communications: An International Journal. V.6, n.4, p. 205-216, 2001. Disponível em: $<$ http:// www.periodicos.capes.gov.br>. Acesso em: 28 outubro 2004.

KENNEDY, S. H. Nurturing corporate image. European Journal of Marketing. V.11, n.3, p.120-164, 1977. Disponível em: <http:// www.periodicos.capes.gov.br >. Acesso em: 01 setembro 2004.

KOSSLYN, S. S.; et al. Sobre la desmitificación de las imágenes mentales. In: RODRÍGUEZ, J. J. O. Imágenes mentales. Barcelona: Paidós, 1996

KOTLER, P. Administração de marketing: análise, planejamento, implementação e controle. 5. ed. São Paulo: Atlas, 1998.

KOTLER, P.; FOX, K. F. A. Marketing estratégico para instituições educacionais. São Paulo: Atlas, 1994.

LAUNDRUM, R. E.; TURRISI, R.; HARLESS, C. University image: the benefits of assessment and modeling. Journal of Marketing for Higher Education. V.9, n.1, p.53-68, 1998. Disponível em: <http:// www.periodicos.capes.gov.br>. Acesso em: 28 outubro 2004.

LEDOUX, J. O cérebro emocional: os misteriosos alicerces da vida emocional. Rio de Janeiro: Objetiva, 2001.

LEMOS, F. Memória em jogo. Revista Vida e Saúde. Tatuí-SP, ano 64, n.7, julho 2002.

LÉVY, p. As tecnologias da inteligência: o futuro do pensamento na era da informática. Tradução de Carlos Irineu da Costa - Rio de Janeiro: Ed. 34, 1993. 208p.

LOUNDON, D.; DELlA BITTA, D. Comportamiento del consumidor: Conceptos y aplicaciones. McGraw-Hill, México City, 1995.

MALHOTRA, Naresh. Pesquisa de marketing: uma orientação aplicada. Tradutor: Nivaldo Montingelli Jr. E Alfredo Alves de Farias. 3. ed. Porto Alegre: Brookman, 2001.

MARCHETTI, R. Z.; PRADO, P. Avaliação da satisfação do consumidor utilizando o PLS: um modelo aplicado ao setor elétrico brasileiro. In: ENCONTRO ANUAL DA ANPAD, 25., 2001, Campinas. Anais... Campinas: ANPAD, 2001.

MASLOW A. H. Motivation and Personality. New York, Harper \& Row, 1952.

MAY, E. G. Practical applications of recent retail image research. Journal of Retailing. V.50, n.4, p. 15-20, 1974. Disponível em: <http:// www.periodicos.capes.gov.br $>$. Acesso em: 26 novembro 2004. 
MAZURSKY, D.; JACOBY, J. Exploring the development of store images. Journal of Retailing. n. 62, p.145-165, 1986. Disponível em: <http:// www.periodicos.capes.gov.br $>$. Acesso em: 01 setembro 2004.

MELO, M. S.; VIERIA, P. R. C. Imagem corporativa e investimento na preservação do meio ambiente: a nova tendência da agenda estratégica. In: ENCONTRO ANUAL DA ANPAD, 28. 2004, Curitiba. Anais... Curitiba: ANPAD 2004.

MELO, M. S.; VIERIA, P. R. C. Imagem corporativa e investimento na preservação do meio ambiente: a nova tendência da agenda estratégica. In: ENCONTRO ANUAL DA ANPAD, 28. 2004, Curitiba. Anais eletrônicos... Curitiba: ANPAD 2004. Disponível em: $<$ http://www.anpad.org.br>. Acesso em: 07 fevereiro 2004.

MORGAN, G. Imagens da organização: Edição executiva. São Paulo: Atlas, 2000.

MOSCOVICI. S. A representação social da psicanálise. Rio de Janeiro: Zahar, 1978.

MÜlLER, G. R. Fatores que determinam o sucesso de cursos de graduação. 2005. Dissertação (Mestrado em Engenharia de Produção) - Departamento de Engenharia de Produção e Sistemas (EPS), Universidade Federal de Santa Catarina, Florianópolis, 2005.

NEVES, A. B. Os impactos dos resultados do Exame Nacional de Cursos na imagem institucional. In: ENCONTRO ANUAL DA ANPAD, 24., 2000, Florianópolis. Anais eletrônicos... Florianópolis: ANPAD 2000. Disponível em: <http://www.anpad.org.br>. Acesso em: 10 de maio 2004.

NEVES, A. B; RAMOS C. F. A imagem das Instituições de Ensino Superior e a qualidade do ensino de graduação: a percepção dos acadêmicos do curso de administração. Revista de Economia e Administração. v.1, n.1, p. 75-84, 2002.

NGUYEN, N.; LEBLANC, G. Image and reputation of higher education institutions in student's retention decisions. The international Journal of Education Management Bradford. V.15, p. 303-311, 2001. Disponível em: <http:// www.periodicos.capes.gov.br >. Acesso em: 28 outubro 2004.

NICOLAO, L.; ESPARTEL, L. B. Julgamentos pós-escolha do curso de Administração: o papel da qualidade percebida, da satisfação e do arrependimento e os seus comportamentos subseqüentes. In: ENCONTRO ANUAL DA ANPAD, 28, 2004, Curitiba. Anais eletrônicos... Curitiba: ANPAD, 2004. Disponível em: <http://www.anpad.org.br>. Acesso em: 10 de maio 2004.

PALÁCIO, A. B. MENESES, G. D. PEREZ, P. J. P. The configuration of the university image and its relationship with the satisfaction of students. Journal of Educational Administration. Armidale, v. 40, p. 486-505, 2002. Disponível em: <http:// www.periódicos.capes.gov.br>. Acesso em: 28 outubro 2004.

PARAMESWARAN, R.; GLOWACKA, A. E. University image: an information processing perpesctive. Journal of Marketing for Higher Education. V.6, n.2, 1995. Disponível em: $<$ http:// www.periodicos.capes.gov.br >. Acesso em: 28 outubro 2004. 
REYNOLDS, T. J.; GUTMAN, J. Advertising is image management. Journal of Advertising. v.24, n.1, p.27-37, 1984. Disponível em: <http://www.periodicos.capes.gov.br>. Acesso em: 28 outubro 2004.

RODRÍGUEZ, J. J. O. Imágenes mentales. Barcelona: Paidós, 1996.

ROSSI, C. A. V.; SLONGO, L.A. Pesquisa de satisfação de clientes: o estado-da-arte e proposição de um método brasileiro. In: ENCONTRO ANUAL DA ANPAD, 21., 1997, Rio das Pedras. Anais... Rio das Pedras: ANPAD, 1997.

SCHACTER, D. L. Searching for memory: the brain, the mind, and the past. New York: BasicBooks, 1996.

SCHIFFMAN, L. G.; KANUK, L. L. Comportamento do consumidor. $6^{\text {a }}$ ed. Rio de Janeiro: LTC, 2000.

SCHULER, M.; DE TONI, D. Imagem de produto e comportamento do consumidor: explorando o processo de formação de imagens. In: ENCONTRO ANUAL DA ANPAD, 28, 2004, Curitiba. Anais eletrônicos... Curitiba: ANPAD 2004. Disponível em: $<$ http://www.anpad.org.br>. Acesso em: 10 de maio 2004.

SHAPIRO, S.; KRISHNAN, S. Memory-based measures for assessing adverstising effects: a comparison of explicit and imoplicit memory effects. Journal of Advertising, v. 2, n.3, Fall, 2001. Disponível em: <http:// www.periodicos.capes.gov.br>. Acesso em: 28 outubro 2004.

SOUKI, G. Q.; PEREIRA, C. A. Satisfação, motivação e comprometimento de estudantes de administração: um estudo com base nos atributos de uma instituição de ensino superior. In: ENCONTRO ANUAL DA ANPAD, 28, 2004. Curitiba. Anais eletrônicos... Curitiba: ANPAD, 2004. Disponível em: <http://www.anpad.org.br>. Acesso em: 10 de maio 2004.

STERNBERG, R. J. Psicologia cognitiva. Porto Alegre: Artes Médicas Sul, 2000.

STILLINGS, N. A. et al. Cognitive science: an introduction. Cambridge: The MIT Press, 1995.

TRIVIÑOS, A. N. S. Três enfoques na pesquisa em ciências sociais: o positivismo, a fenomenologia e o marxismo. In: __. Introdução a Pesquisa em Ciência Socias: a pesquisa qualitativa em educação. São Paulo: Atlas, 1987, p.30-56.

URDAN, A. T.; RODRIGUES, A. R. O modelo do índice de satisfação do cliente norteamericano: um exame inicial no Brasil com equações estruturais. In: ENCONTRO ANUAL DA, 22., 1998, Foz do Iguaçu. Anais... Foz do Iguaçu: ANPAD, 1998.

VOLLE, M. Analyse des Données. 3. ed. Paris : Ed. Economica, 1985.

WILKIE, William L. Consumer behavior. New York: John Wiley \& Sons, 1994.

WOOD JR., T., ZUFFO, P. K. Supply Chain Management. Revista de Administração de Empresas. São Paulo, v.38, n.3, p.55-63, jul/set., 1998. 